\title{
Helping the Next 4 Billion Go Online Part II: Prototyping Solutions for Digital Literacy Education
}

\author{
Victor Udoewa \\ Deputy Director of 18F Learn \\ Washington, DC 20006 \\ victor.udoewa@gsa.gov \\ *Corresponding Author
}

Lea Bauer

Head of German Markets

Udemy

San Francisco, CA 94107

Lea.bauer@udemy.com

\footnotetext{
Parivartika Patel

Quality Assurance Analyst

ZS Associates

Pune, Maharashtra

parivartika.patel@gmail.com
}

\author{
Neil Mathew \\ Graduate \\ Amity University \\ Uttar Pradesh, India \\ mathew.neil@gmail.com
}

\author{
Lokesh Bhog \\ Technology Specialist \\ NIIT Gurugram \\ Haryana, India 122001 \\ lokeshb@niit.com
}

\author{
Anuranjan Gupta \\ Student \\ NIIT \\ New Delhi 110087, India \\ anuranjannet@gmail.com
}

\author{
Bhawana Prabhakar \\ Project Engineer \\ Wipro Technologies \\ Greater Noida, India 201308 \\ bhawanaprabhakar@gmail.com
}

\begin{abstract}
In 2015, over two hundred million people, around the world, went online for the first time bringing the number of people worldwide using the Internet to 3.2 billion. Still, a majority of the world, about 4.2 billion, is offline. The barriers to going online and becoming digitally literate can be greater than just infrastructural obstacles, including psychosocial barriers related to incentives, affordability, and user capability. Our goal is to help the next 4 billion go online by designing an educational solution to equip people with digital literacy skills to improve their lives. We have employed a human-centered design methodology through community research, synthesis, ideation, prototyping, and piloting to build solutions first for northern and central India. The design may be re-contextualized in order to scale to new locations. This paper focuses on the ideation and prototyping parts of the design phase and the initial pilots of the delivery phase, which are still in progress.
\end{abstract}

Index Terms - Digital literacy, Educational curricula, Human-centered design, India

\section{INTRODUCTION}

In today's knowledge economy, it is possible to find older information in physical libraries. But with so much new information available online, and some of it only online, it is increasingly important to have access to online information in order to fully participate in this economy and 
benefit from its knowledge. This idea is supported by various studies indicating a high correlation between a country's Internet access or use and a country's gross national income (GNI) per capita or $\mathrm{GDP}^{1-7}$. It is for this reason that one area of international and community development is development of information and communication technologies (ICTs). One obvious barrier to ICT is the lack of physical infrastructure ${ }^{8}$. This includes subterranean fiberoptic networks as well as maritime, seafloor cables connecting various continents and coastal points. Additionally, this includes infrastructure related to mobile phone networks like cell phone towers.

But even with a mobile network or an underground fiber-optic network, an often forgotten, large part of physical access is device access ${ }^{8}$. Today a majority of the world accesses the Internet through a mobile device ${ }^{9}$. This includes people who have never accessed the Internet through a laptop or desktop computer. They are using tablets, smartphones (Tier-1 phones with full Internet capability) and feature phones (Tier-2 phones with limited Internet capability). Today, with large decreases in the retail price of smartphones, illustrated by Mozilla's shortlived, \$33 smartphone first launched in India in 2014, Internet-capable mobile phones are providing more and more people access to the Internet for the first time ${ }^{10}$.

In 2013, 243 million people came online for the first time, primarily through mobile phones $^{11}$. In 2014, over 250 million people came online bringing the number of people using the

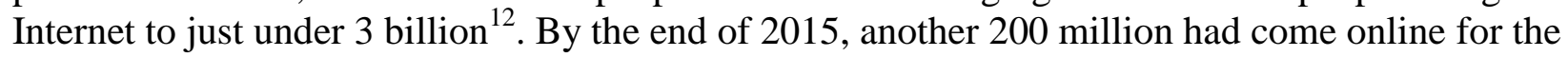
first time bringing the total number of people online to 3.2 billion, over $40 \%$ of the world's population $^{1,13}$. However, the majority of the world is still offline - about 4.2 billion people - and still not enjoying the correlated benefits of the Internet and of participating in a wider knowledge economy ${ }^{1,14}$.

An important concept to note is the definition of "online" used here from the International Telecommunications Union (ITU) ${ }^{15}$. It is defined as having "accessed the Internet at least once in the past 12 months from any kind of device." This means that not everyone considered "offline," lacks physical, infrastructural access. For example, imagine an elderly person in a rich country whose neighborhood has Internet access but who has never started using the Internet. So the 4.3 billion offline people-group includes people with physical, infrastructural access. On the other hand, not everyone counted as "online" is truly online. Imagine, a young woman from a rural area in sub-Saharan Africa who traveled to the medium-sized town once last year and borrowed someone's mobile phone for 15 minutes playing with Facebook for the first and only time last year. In a similar manner, the almost 3 billion online people-group includes people who are not habitually "online" and definitely includes people who use it but are not sufficiently digitally literate.

These two examples and corresponding limitations of the ITU's measurement imply two things. First, digital literacy education is needed and helpful for portions of the almost 3 billion online people. In other words, being online does not imply being digitally literate. Secondly, and most importantly, as the example of an offline, elderly person in a rich country demonstrates, lack of physical, infrastructural access is not the only barrier to being online and becoming digitally literate. In broad terms, barriers to going online can be grouped into four broad categories (Table 1$)^{8}$. 
TABLE I

BARrIERS TO GoING ONLINE

\begin{tabular}{|l|l|}
\hline Incentives & Affordability \\
\hline $\begin{array}{l}\text { Lack of time } \\
\text { Irrelevance } \\
\text { Lack of awareness } \\
\text { Lack of socio-cultural acceptance } \\
\text { Fear }\end{array}$ & High price \\
\hline User Capability & \\
\hline $\begin{array}{l}\text { Lack of ability with digital tools } \\
\text { Lack of English literacy } \\
\text { Lack of dominant language literacy } \\
\text { Difficulty of using/learning the Internet }\end{array}$ & $\begin{array}{l}\text { Infrastructure } \\
\text { Lack of consistent power } \\
\text { Lack of mobile Internet coverage } \\
\text { Lack of device access }\end{array}$ \\
\hline
\end{tabular}

Educational outreach initiatives, which focus on digital literacy education, can directly or indirectly address all categories of barriers. An example is a mobile Internet bus with educational classes and games. It provides device access, mobile Internet coverage, consistent power and free access for people from low-income neighborhoods while increasing awareness and competency, teaching relevance and how to create relevant content, and affecting acceptance while decreasing fear. Some educational outreach initiatives focus on one barrier or category of barriers, like a radio or TV awareness campaign and some, like a mobile bus, focus on multiple barriers at the same time. Ultimately, the aim of our Google's ICT educational outreach initiatives is digital literacy and digital inclusion for those who are offline.

Google, a large multi-national Internet technology (IT) corporation, has natural incentives to increase digital inclusion and increase the number of people who are digitally literate worldwide. When there are more people who are digitally literate, then there will be more people who can access and will use our tools. Also, Google wants people who come online for the first time to use our products rather than a competitor's products. The drawbacks of this motivation is that our digital literacy work is largely focused on our digital literacy tools rather than being toolagnostic. The benefits of doing this work with the support of our large multi-national corporation is access to sufficient funding for the work and access to a wide network of collaborators on both international and local levels. Fortunately, Google's profit motivations, though different, are aligned with the altruistic motivations of employees who completed this work as a side project, not a highly prioritized project within Google. Moreover, Google did not affect the approaches used. The first author is the only instructional designer in the organization using the approach used in this paper, so our approach is unorthodox and not well supported within instructional design community in Google. However, our team felt our approach was best for the research questions we are working to solve in the area of digital literacy.

\section{Contextualizing Digital Literacy}

It is not enough to simply be online in order to benefit from the knowledge therein; one must also become digitally literate to navigate, find, and take full advantage of this online knowledge. In 
order to assess whether a person is digitally literate or not or what percentage of a country is digitally literate, we must first define digital literacy. Currently there is no one definition of digital literacy around the world. This makes sense in light of the fact that in different countries and contexts people need to be able to do different things in life, with or without digital tools. So the relevance and importance and even use of digital tools changes in different spaces and places.

To give an example, one of the authors advises the Tinder Foundation in collaboration with the UK government in an effort to make $100 \%$ of UK adults, aged 16 and higher, digitally literate by the year $2020^{16}$. In order to assess whether that goal is met, they had to define digital literacy in a UK context. Let us follow an example of how one criterion for UK digital literacy was designed $^{17}$.

1. First, being a rich country, most of those who are not digitally literate in the UK fall in two major, non-exclusive categories: the low-income and the elderly.

2. Second, many people in low-income situations in the UK are looking for jobs or want better jobs.

3. Third, most of the jobs in an Internet-friendly country like the UK are online.

4. Therefore, one criterion for digital literacy in the UK is "must be able to find jobs online." Other criteria are defined similarly.

It is this relevant, contextual defining of digital literacy that is much more important than general, context-blind definitions of digital literacy. What should people in this context be able to do if they are digitally literate? That is the question we must answer if we want to assess digital literacy and readiness. Previously, in Google's global digital literacy initiatives, this assessment work was wanting. As a result, we have received a number of criticisms on the Web Academy curriculum, Online Basics ${ }^{18}$. Some found it too long; others found it too short; some, too difficult, others, too easy. It highlighted a problem of context, audience, and targeting. Instead of a general module on "How to Search" or a "Search Engine," we want to be able to have a contextualized module like "Find Jobs Online." Both teach similar skills but one is embedded in the problems and complexities of the lives of people, making it much more relevant.

In this work, our goal was to start over and redesign an educational solution to digital illiteracy in six steps.

1. Choose a local context.

2. Define digital literacy in that context.

3. Define design research questions to pursue.

4. Choose a research methodology.

5. Perform designed-based research.

6. Design and test prototypes of solutions.

We would then use that solution as a master solution or a standard solution that would be recontextualized as we repeat the process in a different geography for a different people-group.

As outlined in the first paper ${ }^{19}$, we chose India as our location because of it's massive offline population, booming economy and growing inequality gap ${ }^{20-25}$. Next, we defined digital literacy ${ }^{26-28}$ with respect to India so as to build a curriculum that is most relevant to our target audience. We chose Human-centered Design as our research methodology because our research 
questions are qualitative in nature, and their answers will inform the design and implementation of a digital literacy solution ${ }^{29-40}$.

The team framed the design challenge and performed design-based research with hundreds of people across 13 communities $^{19}$. Based on the themes, learning theories, analyses, and findings mixed together with other insights, patterns, and frameworks we defined a set of 13 design principles to guide us in our ideation and prototyping work (Table II) ${ }^{19}$.

TABLE II

DESIGN PRINCIPLES

\begin{tabular}{|l|l|}
\hline Number & Principle \\
\hline 1 & Design for mobile. \\
\hline 2 & Separate mobile-based and computer-based modules. \\
\hline 3 & Make it highly visual. \\
\hline 4 & Make it auditory. \\
\hline 5 & Include local languages. \\
\hline 6 & Contextualize in relevant problems. \\
\hline 7 & Make it modular with rapid assessments. \\
\hline 8 & Design for skills. \\
\hline 9 & Design device-based instruction. \\
\hline 10 & Teach learners on the device they will use. \\
\hline 11 & Integrate Internet Safety throughout the curriculum. \\
\hline 12 & Include certification. \\
\hline 13 & Prioritize touchscreen interactions. \\
\hline
\end{tabular}

\section{METHODOLOGY}

Human-centered design is normally broken into three stages, Discover, Design, and Deliver. The first stage (Discover) is a research stage where you listen and learn from the community, developing empathy and connecting yourself to the needs and desires of the community. The second stage (Design) is a stage of data analysis and synthesis of previous qualitative work, followed by ideation, prototyping, and improving iterations. The final stage (Deliver) is the stage of pilot planning, developing a feedback loop, defining success, partnerships, and developing business models for financial viability and sustainability. 
This paper focuses on the prototyping part of the design phase as well as initial pilots of the Delivery phase of the HCD process. Whereas the Discover phase mostly utilized a qualitative research methodology, the prototyping phase primarily utilizes a design experiment methodology ${ }^{40}$. This is because our new research question is whether or not our proposed designs fit the needs of the users. To answer that, we must make prototypes of the design, test it with actual users, evaluate the results, and alter or change the design for the next iteration of testing. The rest of the paper discusses this process of prototyping for digital literacy solutions in northern and central India as well as initial and ongoing pilots.

\section{PROCEDURES AND METHODS}

\section{Analogous Inspiration \& Positive Deviance}

By this point in the process, the design team felt uninspired or unsure of being able to find or create a solution that works after researching so many initiatives that do not work. In order to gain a fresh perspective, we took a slight break before brainstorming in order to shift our focus to inspirational contexts. In the practice of analogous inspiration, an element of a product, interaction, or situation is isolated and then applied to a design challenge.

First, we enumerate any or all activities and behaviors that might be involved in a digital literacy educational experience.

1. Check-in, register

2. Generate an ID

3. Search for an answer

4. Take notes

5. Ask questions

6. Watch videos, songs

7. Discuss with group members

8. Create new ideas

9. Learn new skill

10. Assess progress

Second, for each behavior or activity or for the most important ones, we list different contexts, unrelated to our design challenge, that involve those same activities or behaviors (Table III). 
TABLE III

ANALOGOUS INSPIRATION

\begin{tabular}{|c|c|}
\hline Activity or Behavior & Analogously Inspirational Places \\
\hline \multirow{4}{*}{$\begin{array}{l}\text { Check-in, register, generate } \\
\text { or show an ID }\end{array}$} & Hotels \\
\hline & Colleges \\
\hline & Hospitals \\
\hline & Airports \\
\hline \multirow[t]{6}{*}{ Search for an answer } & Library \\
\hline & Supermarket, store \\
\hline & Railway or bus station \\
\hline & Airport \\
\hline & Newspapers \\
\hline & Cities (info centers), maps \\
\hline \multirow[t]{4}{*}{ Take notes } & Lectures \\
\hline & Shopping (lists) \\
\hline & Debates \\
\hline & Workshops, conferences \\
\hline \multirow[t]{2}{*}{ Watch a video/song } & Cinema, theatre \\
\hline & TV \\
\hline \multirow[t]{2}{*}{ Assess progress } & Sports \\
\hline & Doctor check-up \\
\hline
\end{tabular}

Lastly, we go and observe those activities in the different contexts to be inspired and learn what makes those activities and behaviors work smoothly and well and what makes them difficult. That learning can then be applied to whatever we design in the future. Our design team individually observed the different situations in Table III, taking observational notes and equipping ourselves with ideas which can be useful in the prototyping stage.

A second act of inspiration that the team performed observed was positive deviance. Positive deviance is any example where someone deviates from the norm and has successful results. So 
we were looking for anyone achieving success in digital literacy education through aberrant methods. The design team took a field trip to visit a "Hole in the Wall" station ${ }^{41}$. "Hole in the Wall" stations are locations in which computers are built into the wall and people (mostly children) play and experiment with the computer software in groups, learning and teaching themselves without the aid of a teacher. Interestingly, Dr. Sugata Mitra, the designer of Holes in the Wall, has observed equal or better performance when comparing assessments of children who learned particular content at a "Hole in the Wall" station and children who learned the same content over a number of months with a teacher in a traditional classroom ${ }^{42,43}$.

The design team spent time learning the history, efficacy, and effectiveness of Holes in the Wall, observing the learners, and interviewing the station manager as well as the national manager. Interestingly, the design team learned that out of over 600 "Hole in the Wall" stations, only one is used by adults, alone, in which adult women have become digitally literate. This suggested that the experimental and explorative nature of learners, required for the success of "Holes in the Wall" is more often found among groups of children than adults.

\section{Opportunity Areas and Brainstorming Solutions}

Opportunity areas are gateways to idea generation. Because a solution to any design challenge can open up a number of opportunities, we first brainstorm and choose a small number of opportunity areas to guide our brainstorming. Then we brainstorm in the direction of the opportunity area. Opportunity areas are usually phrased as "how might we" questions and rearticulate a problem or need in a future, open-ended, generative way.

The design team knew that there were many opportunities digital literacy could open up, so we first brainstormed a list of possible opportunities to pursue. We then narrowed the list down to the top 8 and then to the final, top 5 opportunities (Table IV).

TABLE IV

OPPORTUNITY AREAS

\begin{tabular}{|c|l|}
\hline Number & \multicolumn{1}{|c|}{ Opportunity } \\
\hline 1 & How might we empower women through digital literacy education? \\
\hline 2 & $\begin{array}{l}\text { How might we provide digital literacy education and include those who are } \\
\text { not fluent in a dominant language? }\end{array}$ \\
\hline 3 & $\begin{array}{l}\text { How might we provide digital literacy education that is close to people's } \\
\text { homes? }\end{array}$ \\
\hline 4 & How might we enhance socioeconomic status using digital literacy? \\
\hline 5 & How might we use digital literacy education to improve health outcomes? \\
\hline
\end{tabular}

Next, we brainstormed multiple solutions or partial ideas for each of the opportunity areas. We then narrowed our choices to three final brainstormed ideas and assigned 3 or 4 team members to each idea to prototype. 


\section{Prototyping}

\section{Common Service Center (CSC) Integration}

This proposed solutions seeks to integrate digital literacy education into CSCs run by the Network for Computer Information Technology (NICT), the India regional affiliate of TCF ${ }^{44,45}$. All VLEs would offer digital literacy classes and digital services like telemedicine through the CSCs similar to NICT's computer education centers ${ }^{46}$. In addition, people would register and sign in for their courses uses biometric technology to help those with little or no reading-writing literacy. All CSCs would include the following resources and would follow an accountability structure reporting ultimately to the government (Figure I).

1. $100-150 \mathrm{sq} \mathrm{ft}$

2. Minimum of 1 PC with UPS

3. Minimum of 1 printer

4. Digital web camera

5. OS and other application software

6. Genset/Inverter/Solar

7. Broadband connectivity

8. Trained and incentivized manpower

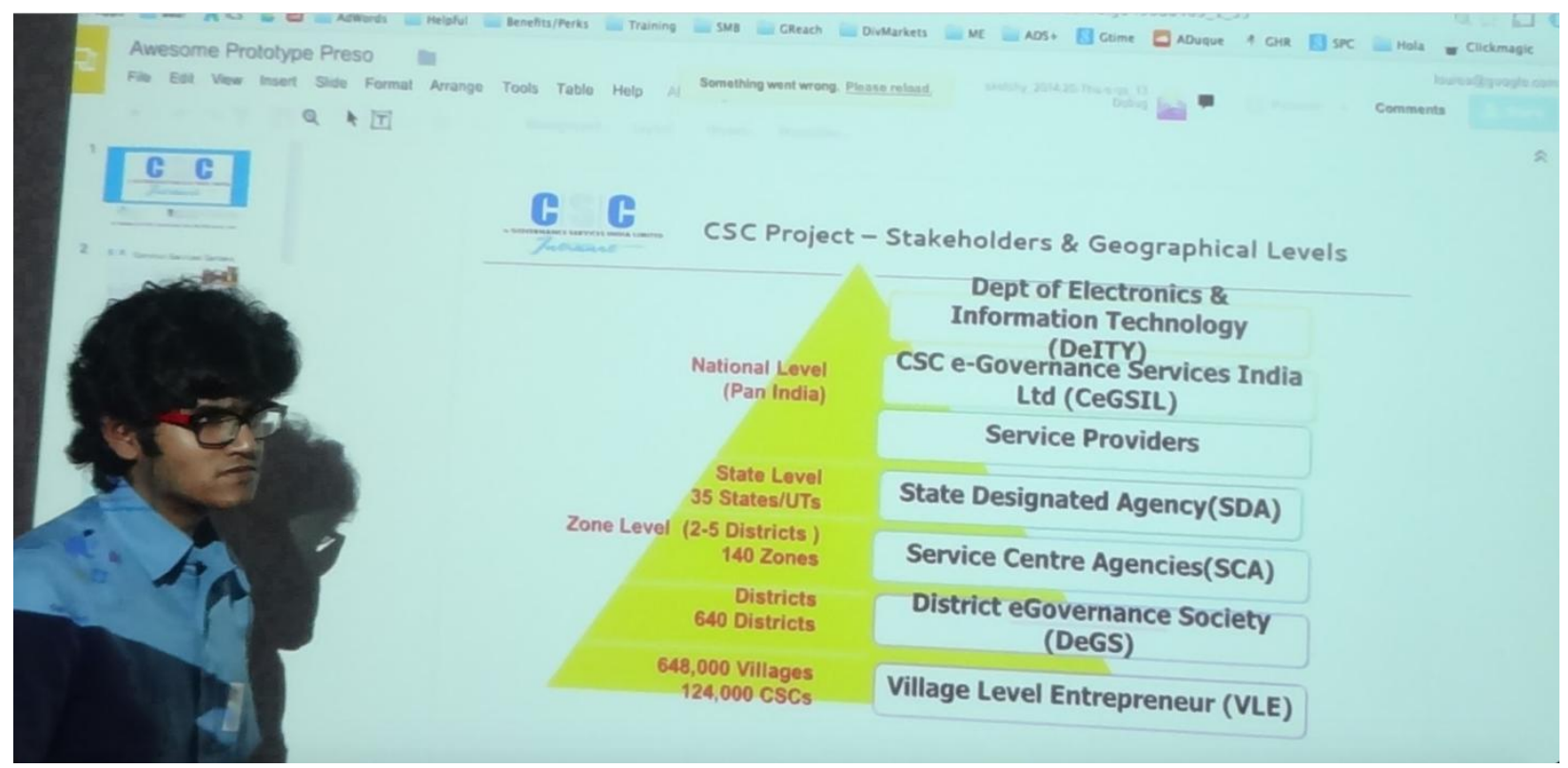

FIGURE I

NEIL PRESENTING CSC GOVERNANCE STRUCTURE

\section{$\underline{\text { Digital Bus }}$}

The digital bus idea focuses on the 6 million people in the greater Delhi area who both have access to the Internet and are literate (Figure II). With 10 busses, 5 areas of Delhi are covered. 
Sixteen people can enter a bus at one time, for 20 minutes at a time. If the busses run for 12 hours a day, each bus can serve 576 people per day. If a bus runs 5 days a week, each bus can serve 11,520 people each month assuming 20 weekdays a month. With 10 busses, that's over 100,000 visits a month which adds up to over a million visits per year.

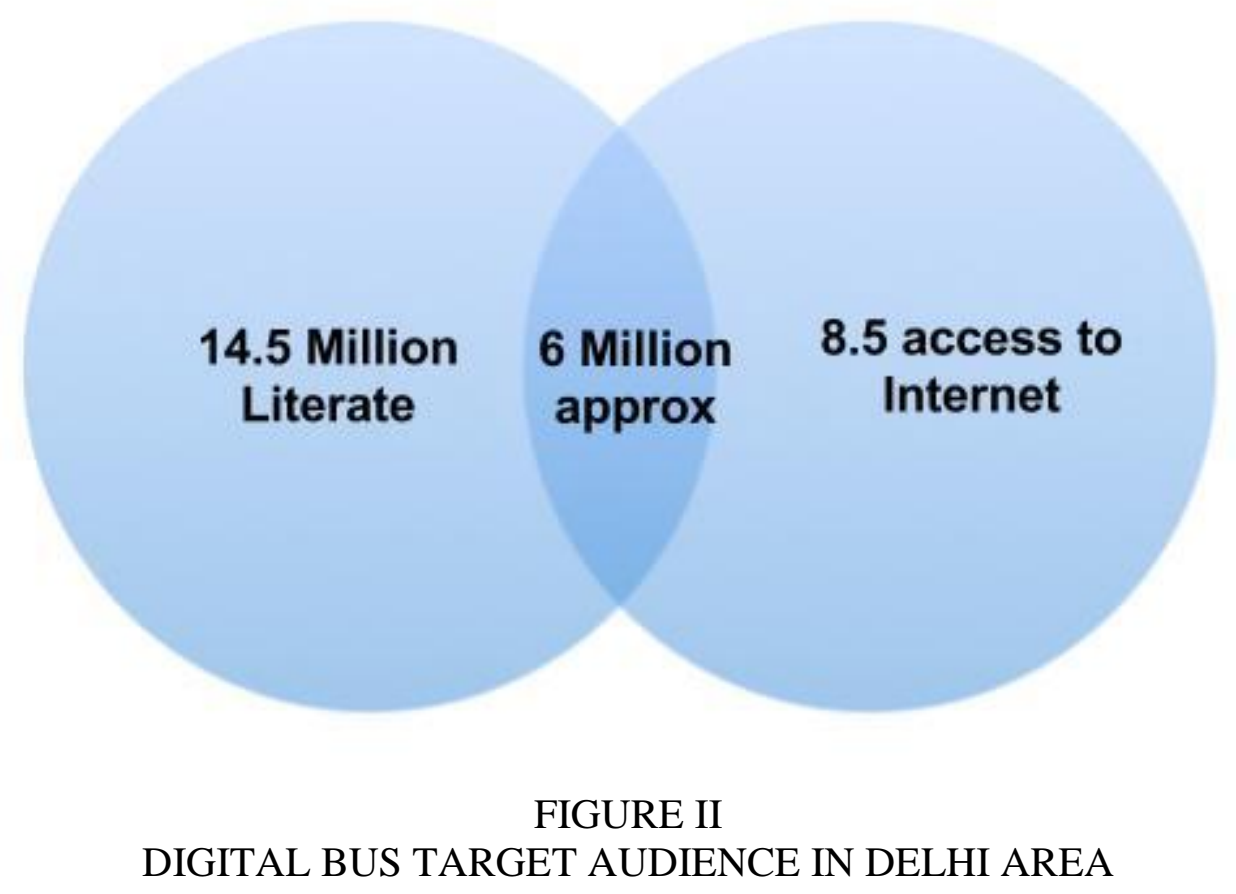

Each bus has 4 areas: a basic station, intermediate station, advanced station, and a showroom (Figures III and IV). Each bus is also staffed by a driver, registration assistant, a nurse, and a learning assistant. A registration code is provided upon entrance of the first visit. There are also supportive printed materials in the bus. At each station, learners can choose between a tutorial or learning module (Figures V and VI). 
International Journal for Service Learning in Engineering, Humanitarian Engineering and Social Entrepreneurship Vol. 12, No. 1, pp. 13-40, Spring 2017

ISSN 1555-9033

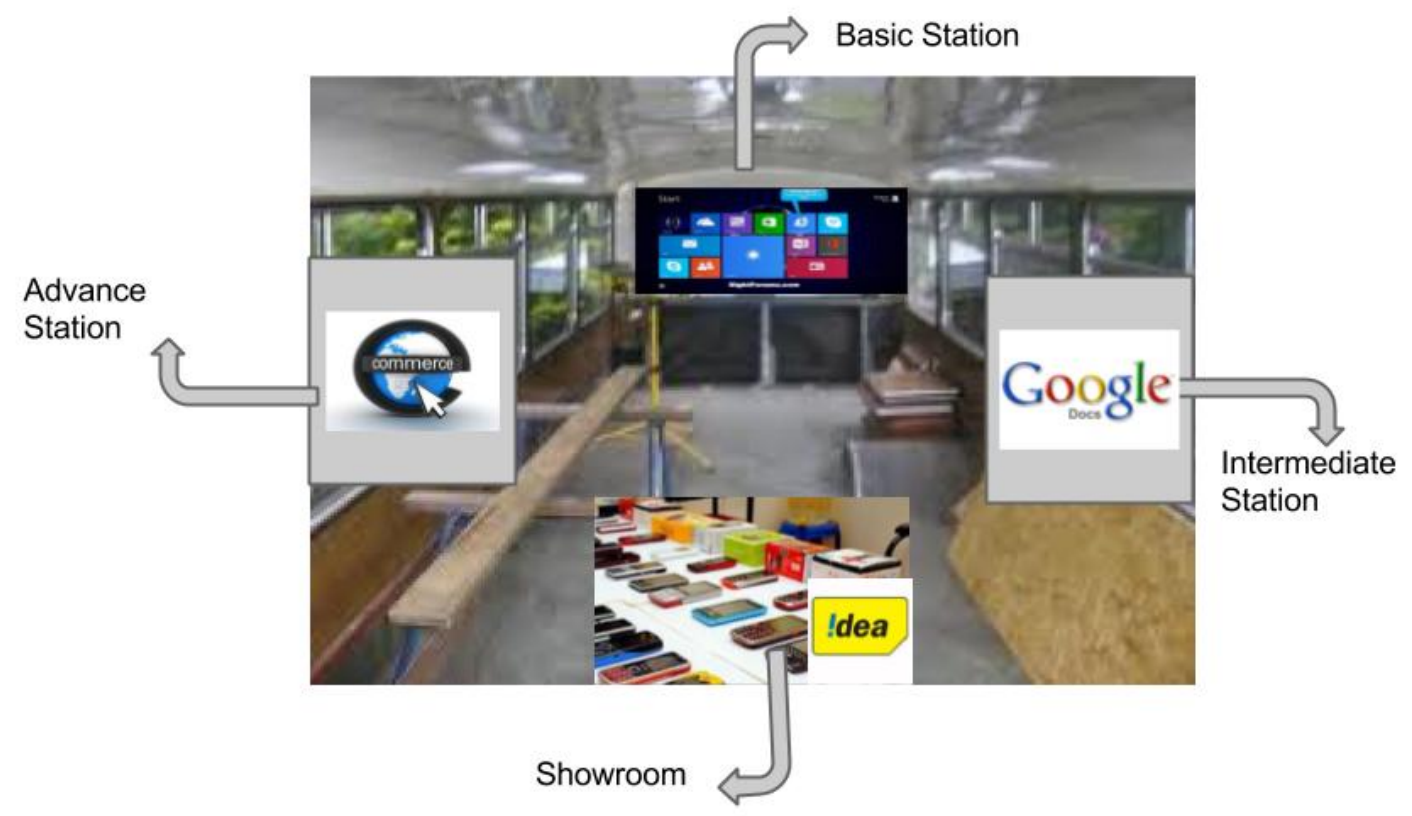

FIGURE III

BUS LAYOUT
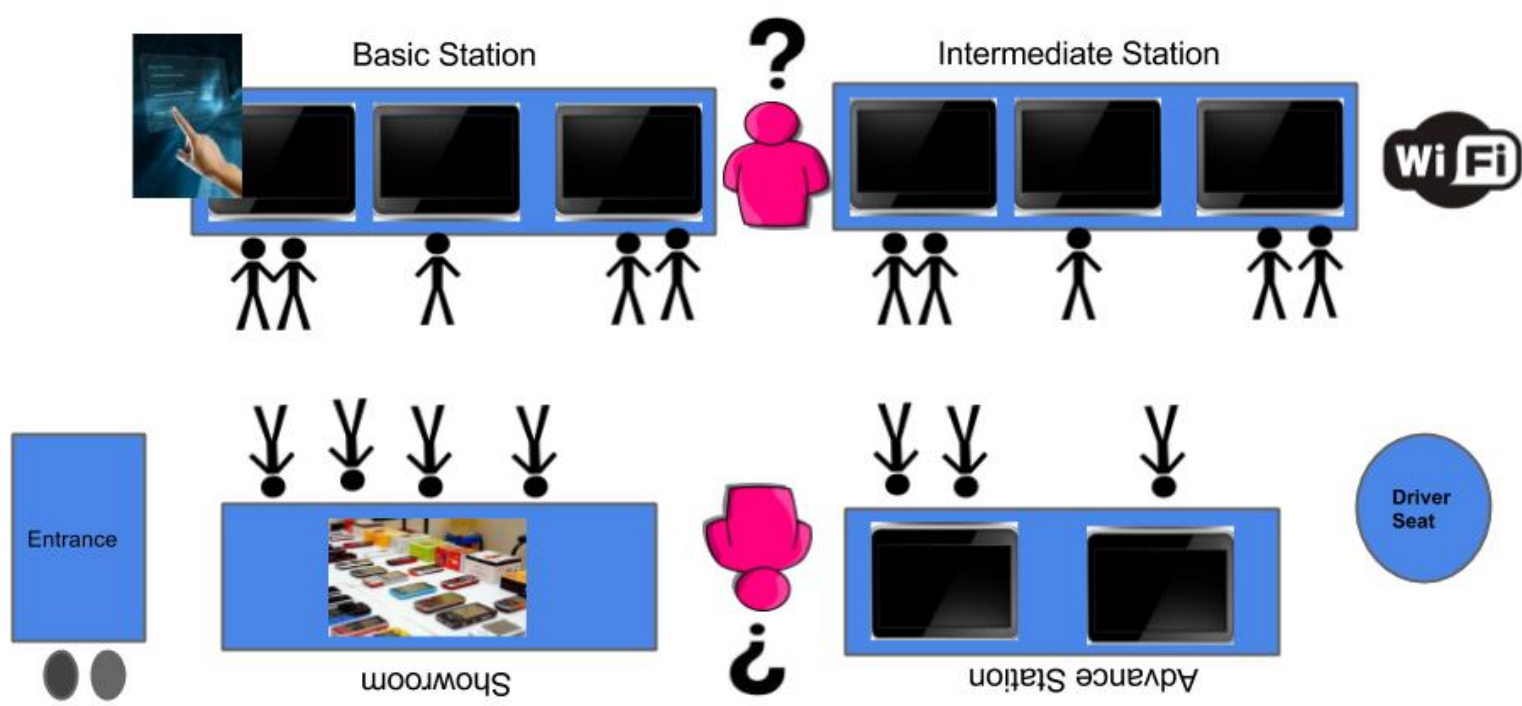

FIGURE IV

BUS STATIONS 


\section{Welcome to the ONLINE Basics Course}

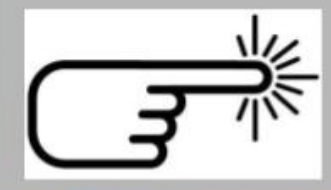

\section{Touch here for a tutorial}

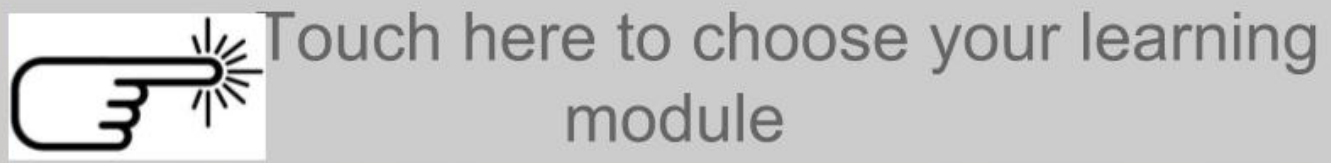

Hardware Basics

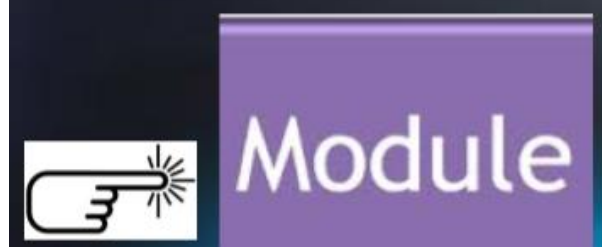

Web Search

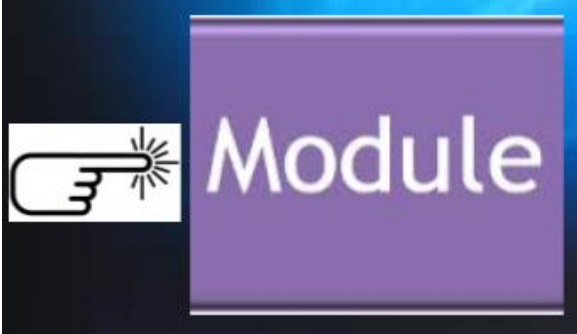

\section{Internet Basics}

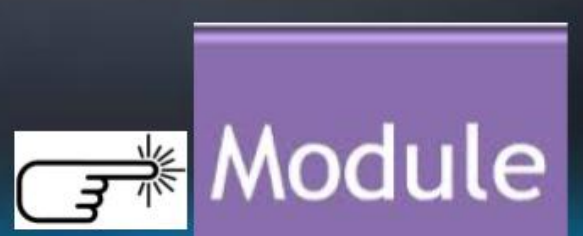

Social Media

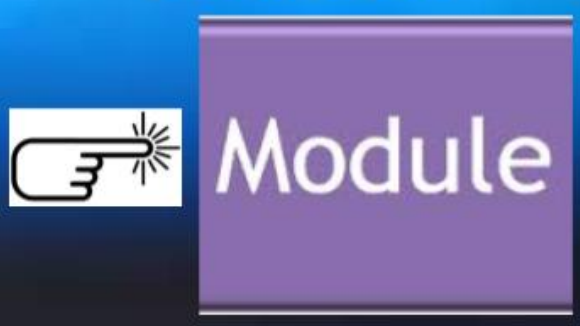

FIGURE VI

LEARNING MODULES - DIGITAL BUS CURRICULUM 
The total fixed costs to acquire the 10 busses is $\$ 1,135,833$ and the cost of running 10 busses for a year is $\$ 2,928,333$. Revenue would come from ads on and in the bus, device sales, and private sponsorships.

Lastly, the digital bus would provide telemedical services - basic health and hygiene information and basic medicine at subsidized rates. The bus program would increase awareness of government health services.

\section{$\underline{\text { Hole-in-a-box }}$}

The Hole-in-a-box idea builds on the Hole-in-the-wall innovation. It is a "box" that offers space for ten individuals to access the internet and computer literacy training materials through touch screens with separate areas for men, women, children, and even medical consultations (Figures VII - X). It uses robust materials to minimize damage from vandalism and is easy to assemble and transport. It is built with mass production components to keep costs low.

The Holes-in-a-box are placed in gathering locations like markets and bus stops in both rural and urban areas. Criteria for placement include foot traffic, power supply, existing infrastructure, etc. The boxes are managed as a non-profit organization financed by ads, corporate sponsorship, and an adopt-a-box program for individual sponsorship. Expenses include energy, hardware, internet access, setup, maintenance and staff.

Each box is managed by a local, trained, female caretaker. The caretaker maintains the equipment and provides help on usage. The non-profit organization pays a stipend to the caretaker.

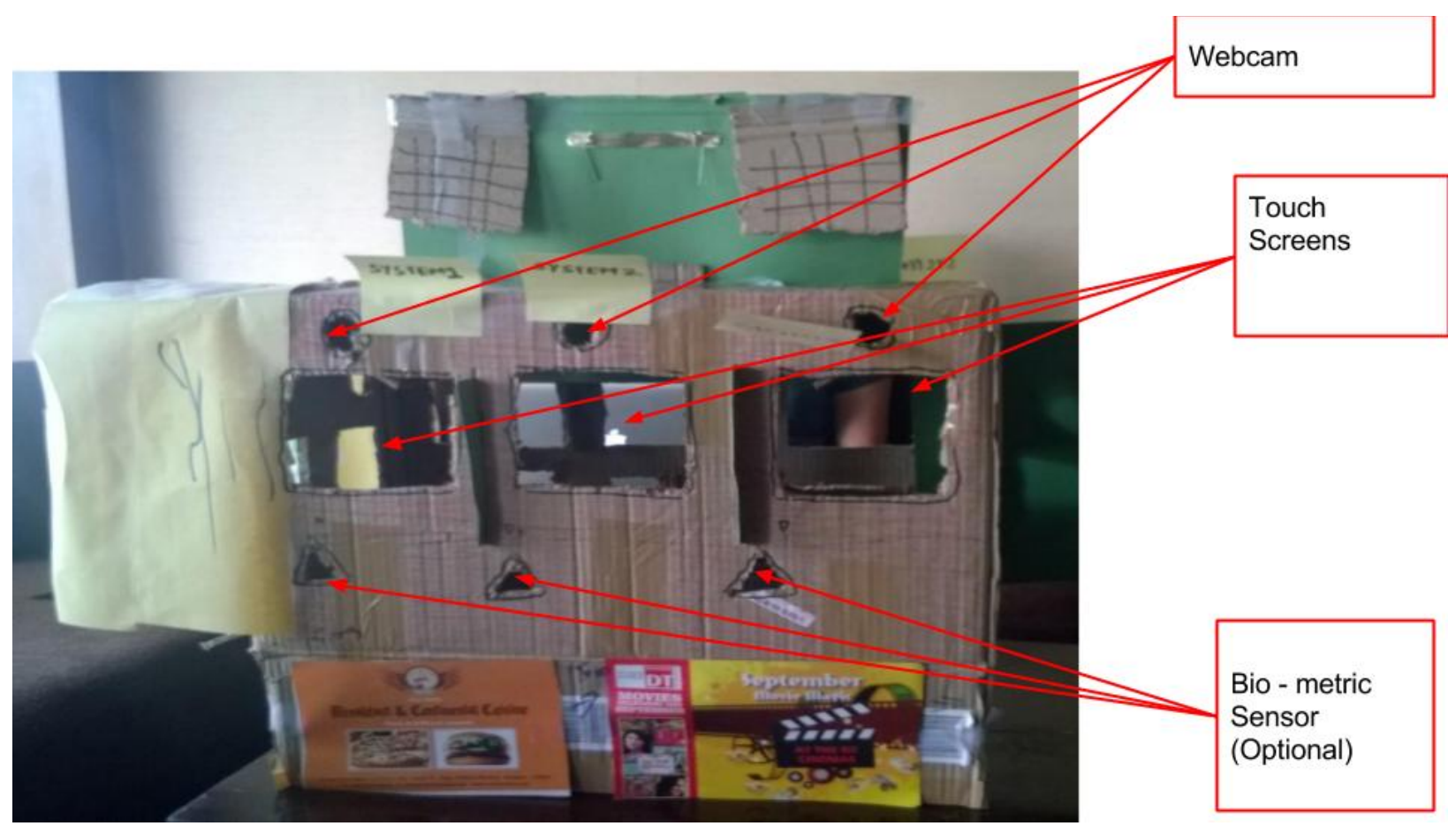

FIGURE VII

LONG SIDE OF HOLE-IN-A-BOX 
International Journal for Service Learning in Engineering,

Humanitarian Engineering and Social Entrepreneurship

Vol. 12, No. 1, pp. 13-40, Spring 2017

ISSN 1555-9033
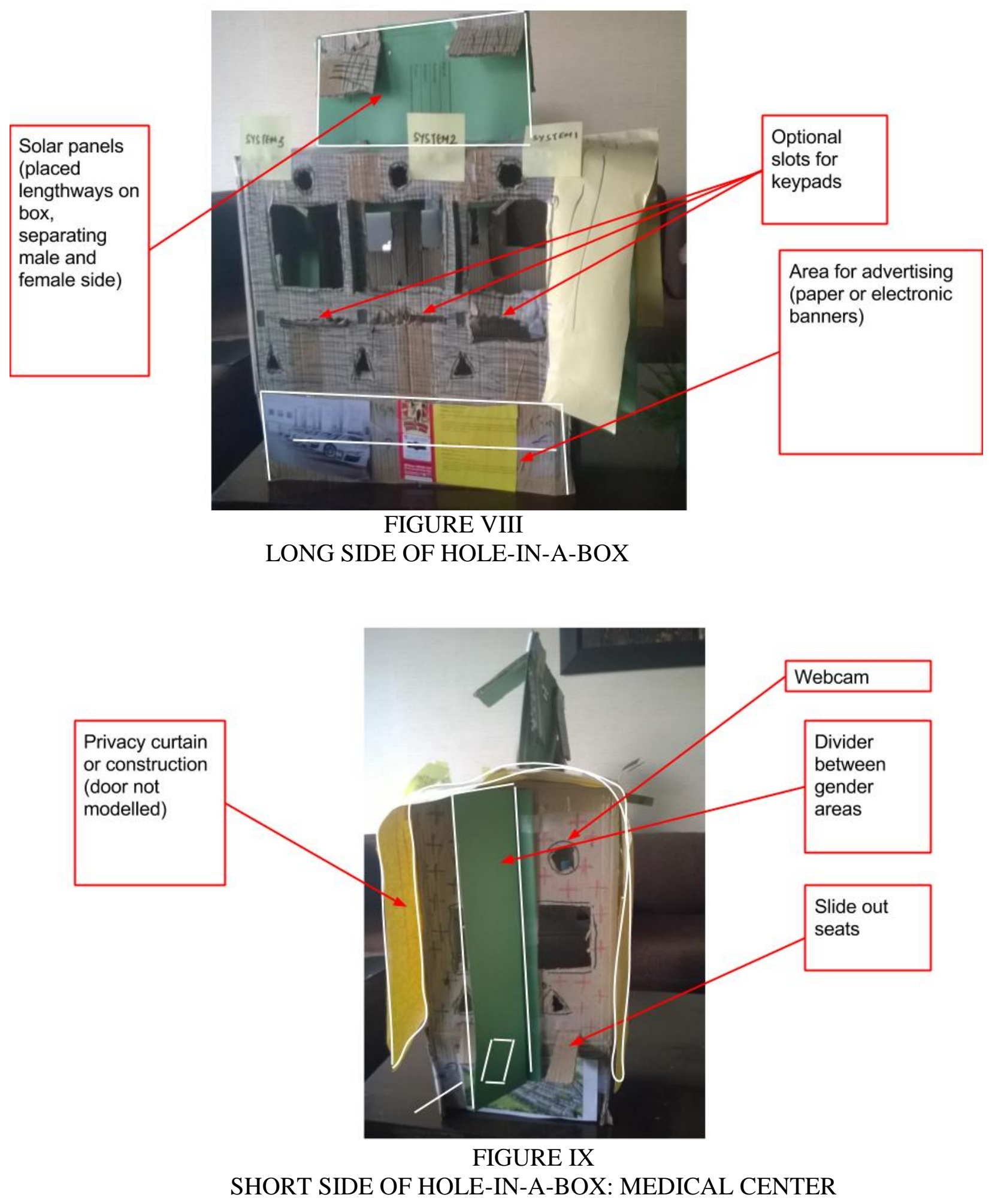


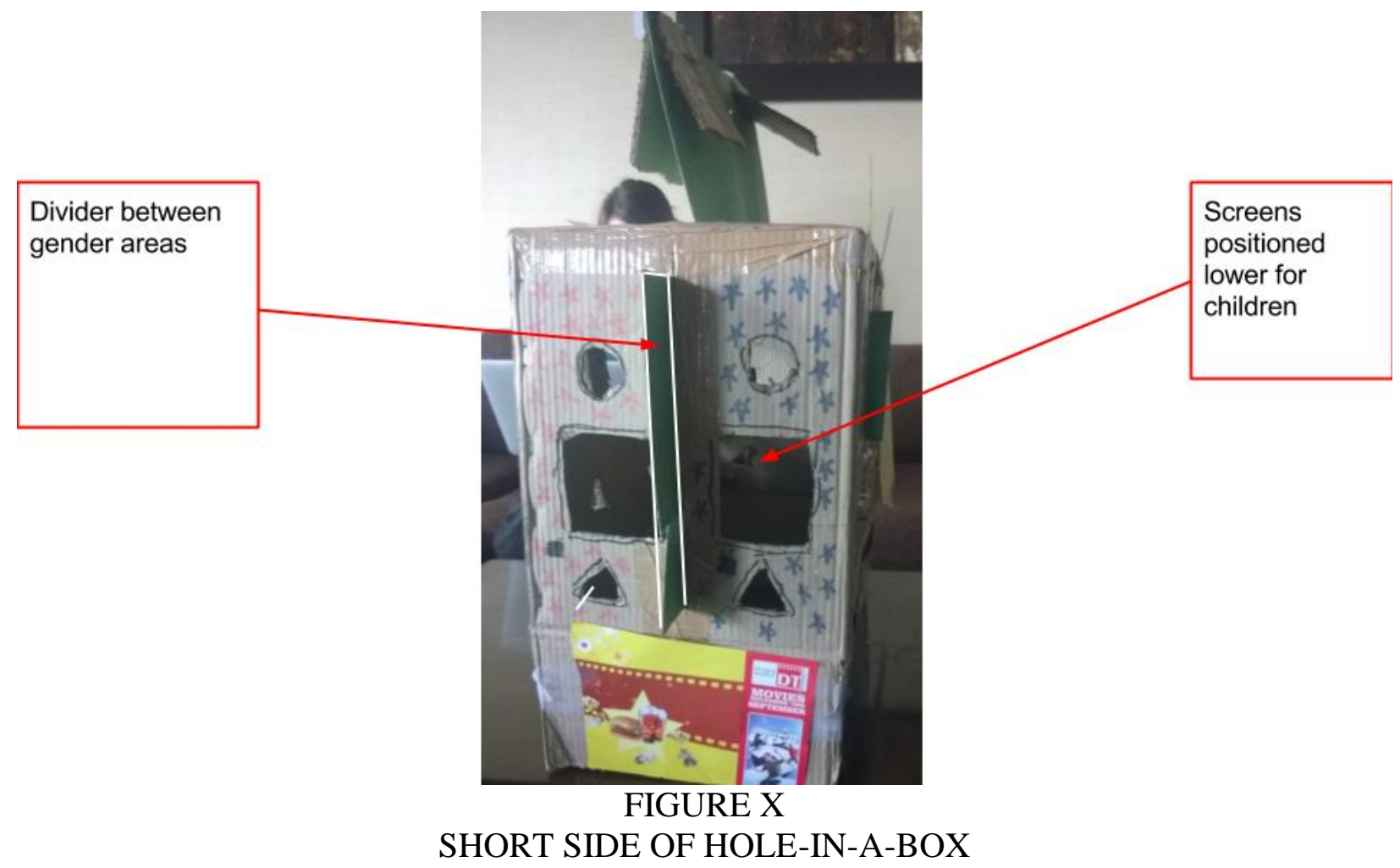

The Hole-in-a-box includes a prototype Hole-in-a-box curriculum that has options for local languages and audio-play for people of low literacy levels (Figure XI). The curriculum allows learning to discover information, connect to others, learn (digital literacy education) or seek medical help (Figure XII). The digital literacy education has three levels - beginning, intermediate, and advanced (Figure XIII).

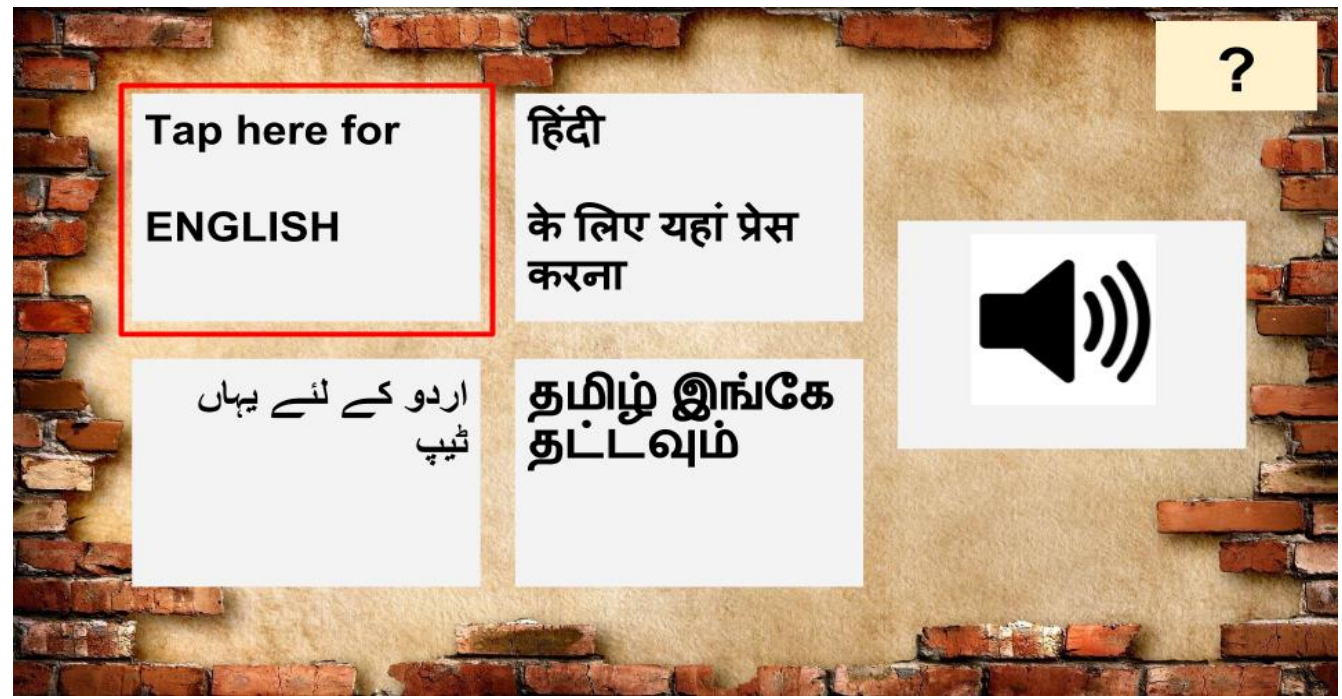

FIGURE XI

HOLE-IN-A-BOX CURRICULUM: WELCOME SCREEN 


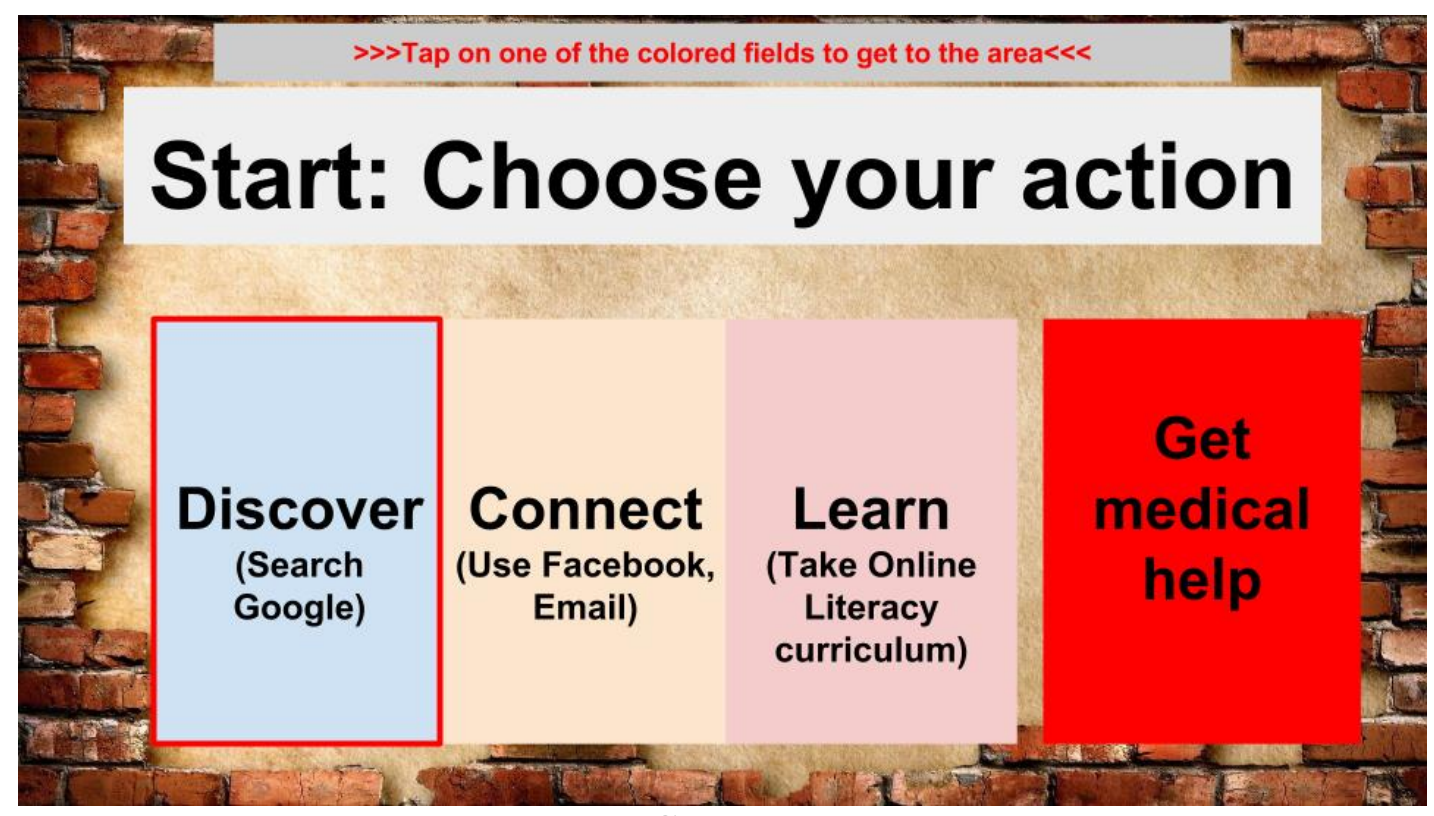

FIGURE XII

HOLE-IN-A-BOX CURRICULUM: LEARNING OPTIONS

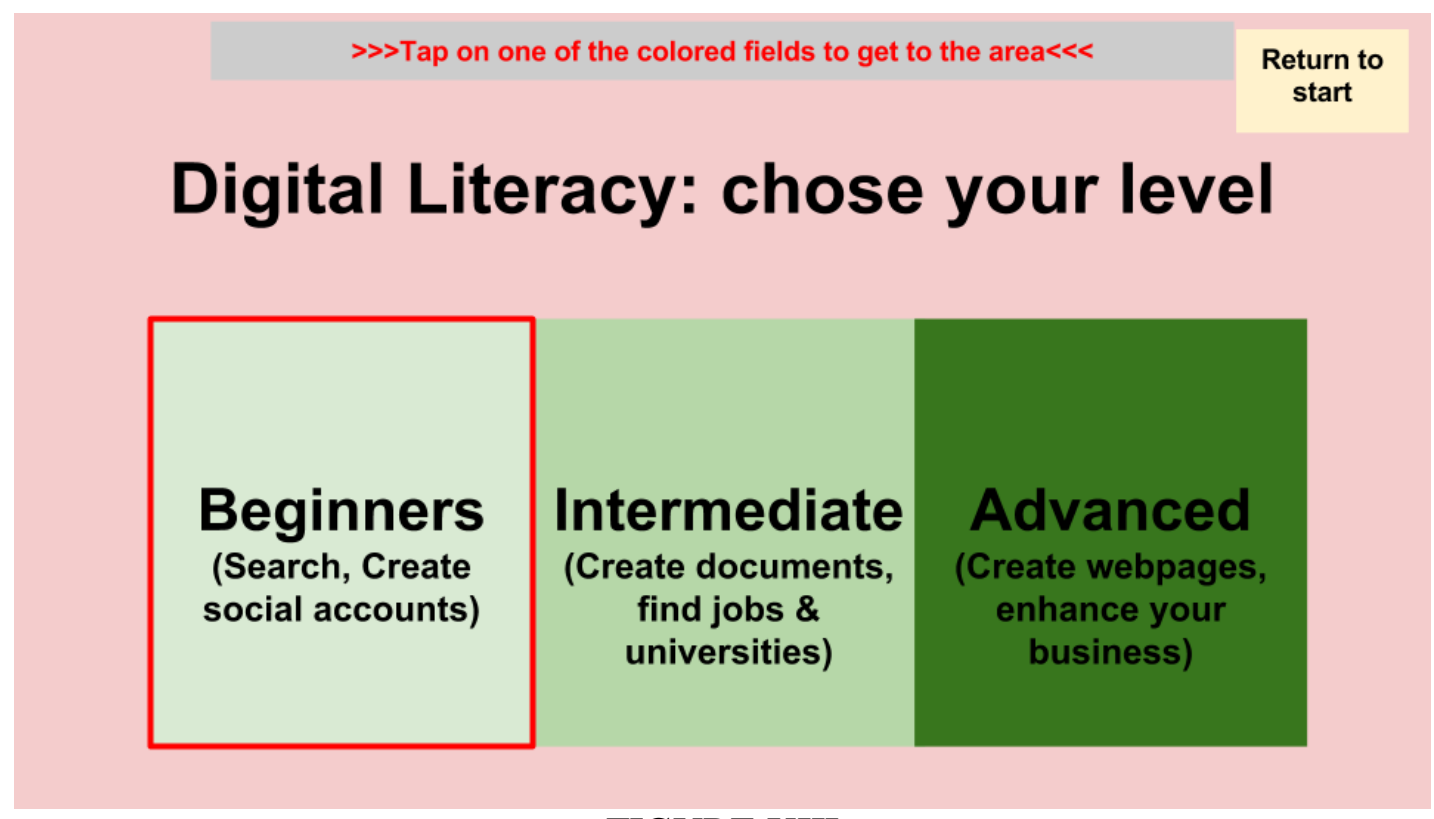

FIGURE XIII

HOLE-IN-A-BOX CURRICULUM: DIGITAL LITERACY LEVELS

Testing Prototypes

The three teams sought qualitative feedback on the prototypes from the same communities who participated in the research. 


\section{Common Service Center (CSC) Integration}

The main concern with NICT staff, VLEs, and experts was the financial model. Currently VLEs do not teach the Web Academy materials because there is no financial incentive. Before this prototype can be taken further, a financial model must be created through which VLEs can bring in funds through the training. However, most people who need digital literacy training do not have disposable income for such trainings. One hundred percent of potential learners, including rural ones, said they would be willing to pay if it provides a good education for their children. However, the prices some could pay may not set up a suitable margin. Without a financial model including expenses it is difficult to determine if it could work. To all experts, this prototype did not make significant advancement from the current situation.

\section{Hole-in-a-box}

Hole-in-the-wall experts gave several points for feedback.

1. Make the interface indestructible to minimize wear.

2. Touch screens might be problematic due to dirty hands and long fingernails in rural areas.

3. Women and girls are likely to get harassed. The caretaker must watch over the interaction.

4. Hardware should be standardized and the number of components minimized to reduce maintenance.

5. Software should be updated centrally

6. Hole-in-the-box curriculum people not interested; adults play?

In addition, $75 \%$ of potential learners were not interested in topics like create documents and create spreadsheets in the intermediate level as well as how to search, social media, and email. They were not relevant, and people did not understand the purpose. Potential learners who did understand the purpose were already emailing or using social media.

One expert pointed out that the exploratory learning of children occurs less in adults and it may be hard for adults to learn through this method without testing it. Only 1 Hole-in-the-wall manifested purely adult learning.

\section{Digital Bus}

All experts who gave feedback felt the financial model was good and possible for a large, multinational company like Google. They also liked the idea of an instructor participating.

All potential learners who gave feedback appreciated having an instructor in the bus. However, similar to the responses to the Hole-in-a-box curriculum, $80 \%$ of people saw no relevance in the module titles.

\section{Merging Prototypes}

After presenting prototypes and feedback results to the rest of the design team, we needed to choose a final prototype to further develop. We decided to evaluate each prototype by how well it met the design challenge, using a summative, multi-dimensional, binary assessment (Table V). 
The Hole-in-a-box was the only prototype that met all constraints; however, both the Hole-in-abox and the Digital bus met a total of 12 constraints and preferences compared to only 8 constraints and preferences satisfied by the CSC model.

TABLE V

EVALUATION OF PROTOTYPES

\begin{tabular}{|l|c|c|c|}
\hline \multirow{2}{*}{ Constraint or Preference } & CSC & Digital Bus & Hole-in-a-box \\
\cline { 2 - 4 } & $1=$ Yes, $0=$ No & $1=$ Yes, $0=$ No & $1=$ Yes, $0=$ No \\
\hline Low-cost to end user & 1 & 1 & 1 \\
\hline Close to end user & 1 & 1 & 1 \\
\hline Updateable & 1 & 1 & 1 \\
\hline Easily set-up & 0 & 0 & 1 \\
\hline time-flexible & 0 & 1 & 1 \\
\hline understandable & 1 & 1 & 1 \\
\hline in Delhi & 1 & 1 & 1 \\
\hline Appropriate duration & 0 & 1 & 0 \\
\hline Interesting & 0 & 1 & 1 \\
\hline Empowering women & 1 & 0 & 0 \\
\hline $\begin{array}{l}\text { Enhance socio economic } \\
\text { status }\end{array}$ & 1 & 1 & 1 \\
\hline Scalable & 0 & 1 & 1 \\
\hline Improving health & 0 & 1 & 1 \\
\hline Continuous access & 1 & 1 & 1 \\
\hline SUM & 0 & 1 & 1 \\
\hline
\end{tabular}

In order to choose a final prototype, the design team could have conducted a weighted multidimensional assessment comparing the Hole-in-a-box to the Digital bus or a higher-order analysis for dimensions like time-flexibility (Hole-in-a-box might be more time-flexible than the Digital bus) or socioeconomic enhancement. Instead the team decided a stronger final prototype takes the best elements of all three initial prototypes, informed by feedback. 
The resulting final prototype is called Drive Digital, a mobile double-decker bus program for northern India. Similar to the Digital bus prototype, Drive Digital is equipped to teach digital literacy to people new to the Internet and computers and phones. It drives around the greater Delhi area on a predefined schedule, and it is equipped with telemedicine services. It is managed similar to the Hole-in-a-box by a primary caretaker who is paid a stipend by a non-profit that manages the bus program and brings in revenue through ads. The caretaker or manager recruits and trains staff for the bus and handles all organizational issues including centralized software updates.

Drive Digital has features that differentiate it from the previous three prototypes and merge features (Figures XIV and XV).

1. Walk-up touch screens with interactive content on the outside of the bus similar to Holein-a-box

2. Separate outside areas for men (A1) and women (A2) like Hole-in-a-box

3. Nurse on staff registering visitors for health visits (C1)

4. Telemedicine video consultation with remote doctors using video equipment (C2)

5. Instructor-led learning on the top floor inside the bus for mixed groups (B)

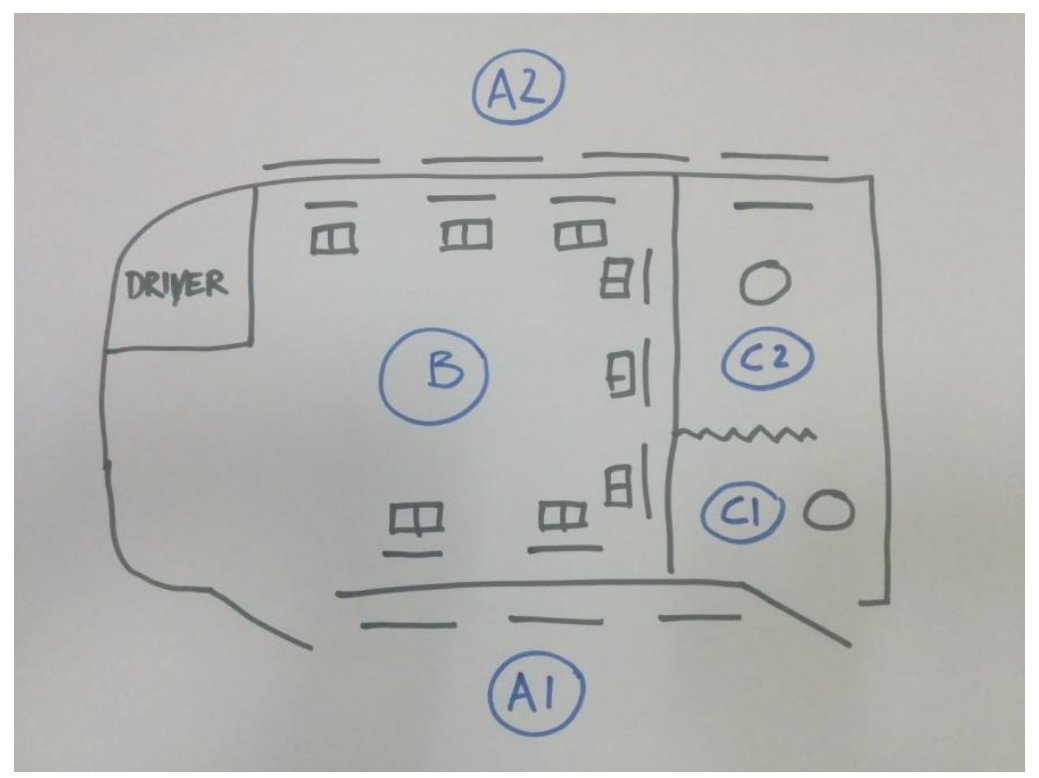

FIGURE XIV

CONCEPTUAL SETUP OF DRIVE DIGITAL 


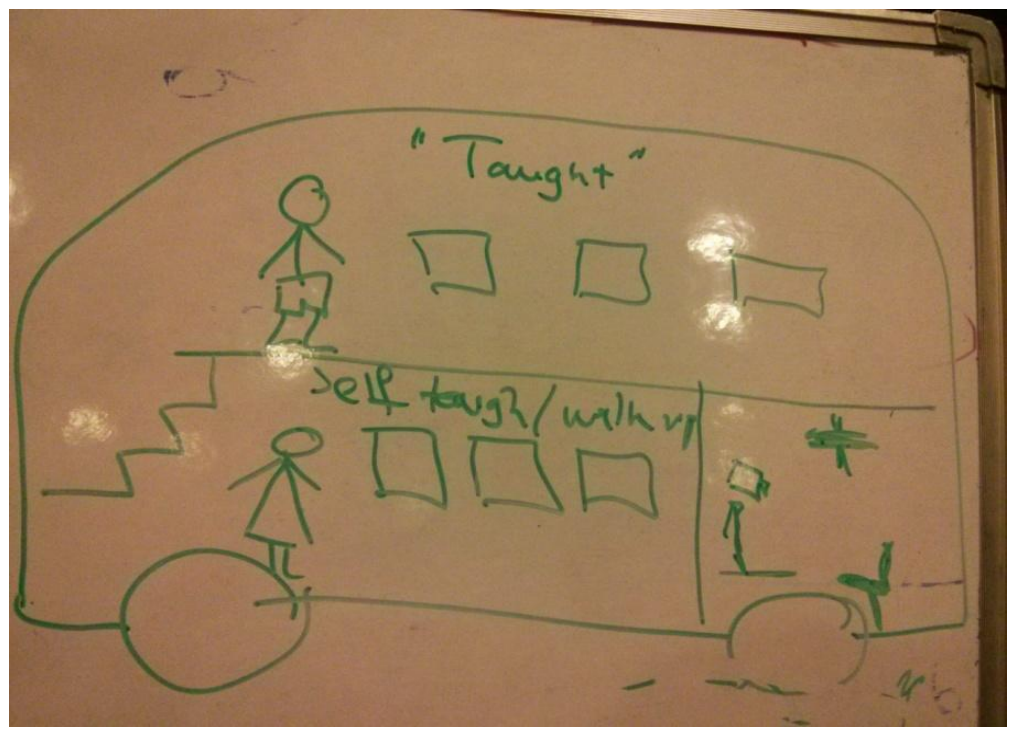

FIGURE XV

\section{LAYOUT DRAWING OF DRIVE DIGITAL}

The expenses and revenue requirements are roughly the same as Digital Bus. However, the Drive Digital curriculum is different from both Digital Bus and Hole-in-a-box prototypes in that it is completely problem-based (Figure XVI and XVII). Even the beginner-level curriculum simply integrates introductions to hardware and the Internet into problem-based modules (Figure XVIII).

\begin{tabular}{|c|c|}
\hline $\begin{array}{l}\text { E-mail account } \\
\text { creation and use }\end{array}$ & Send and receive messages from work and friends \\
\hline G-mail navigation & Find your messages \\
\hline Google Drive & Store your letters, notes, images, and messages \\
\hline $\begin{array}{l}\text { Google Drive } \\
\text { Navigation }\end{array}$ & Find your written letters, notes, and papers \\
\hline Google Docs & Write important notes, letters, and papers \\
\hline Connecting vía video & Make phone calls and see the person you call \\
\hline
\end{tabular}

FIGURE XVI

DRIVE DIGITAL INTERMEDIATE CURRICULUM 
International Journal for Service Learning in Engineering,

Humanitarian Engineering and Social Entrepreneurship Vol. 12, No. 1, pp. 13-40, Spring 2017

ISSN 1555-9033

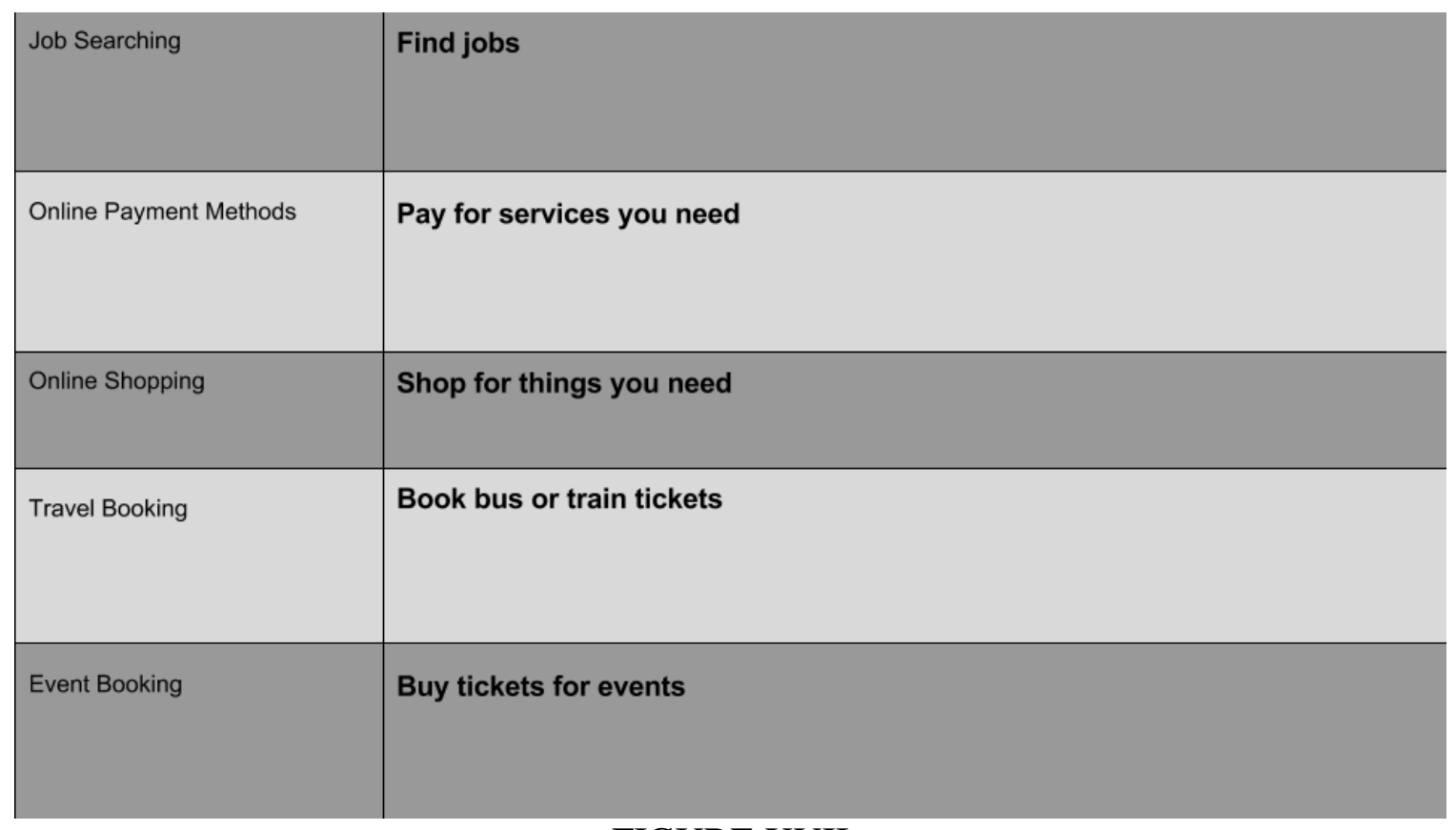

\section{FIGURE XVII}

DRIVE DIGITAL ADVANCED CURRICULUM

\begin{tabular}{|l|l|}
\hline Hardware (integrated) & $\begin{array}{l}\text { How to power up Computer/Mobile device to access Internet (not a module, but } \\
\text { integrated into modules below) }\end{array}$ \\
\hline Internet (integrated) & $\begin{array}{l}\text { What is a Browser? What is a Web Site? } \\
\text { (not a module, but integrated into modules below) }\end{array}$ \\
\hline Searching & Find information when you need it \\
\hline Social Media & Contact and share information with friends and family \\
\hline Entertainment & Listen to music and watch videos \\
\hline $\begin{array}{l}\text { Working on Mobile } \\
\text { Devices }\end{array}$ & Send and receive messages from your phone \\
\hline
\end{tabular}

FIGURE XVIII

DRIVE DIGITAL BEGINNER CURRICULUM 


\section{PILOTING}

Unknown to the design team during the process, Google had previously attempted a mobile Internet bus program in India (Figure XIX - XXI) ${ }^{47}$. However, no information has been found by the design team as to the results or why the program ended.

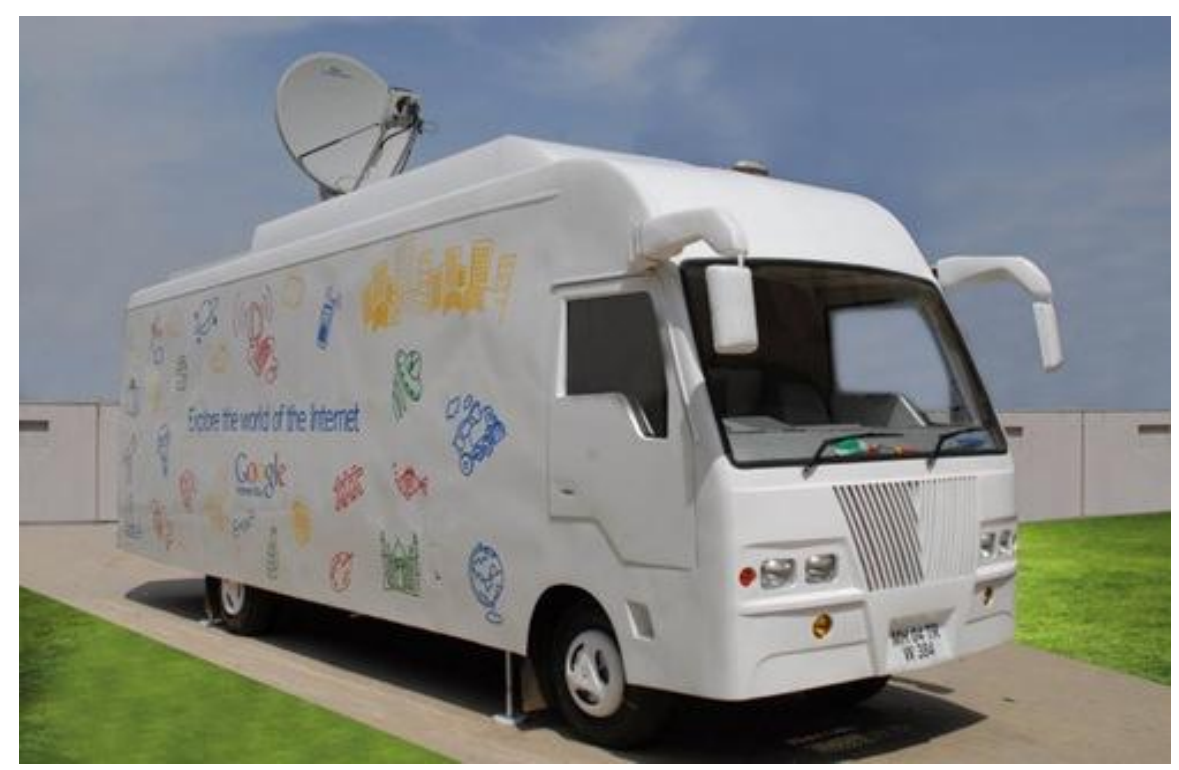

FIGURE XIX

GOOGLE BUS INDIA - EXTERIOR

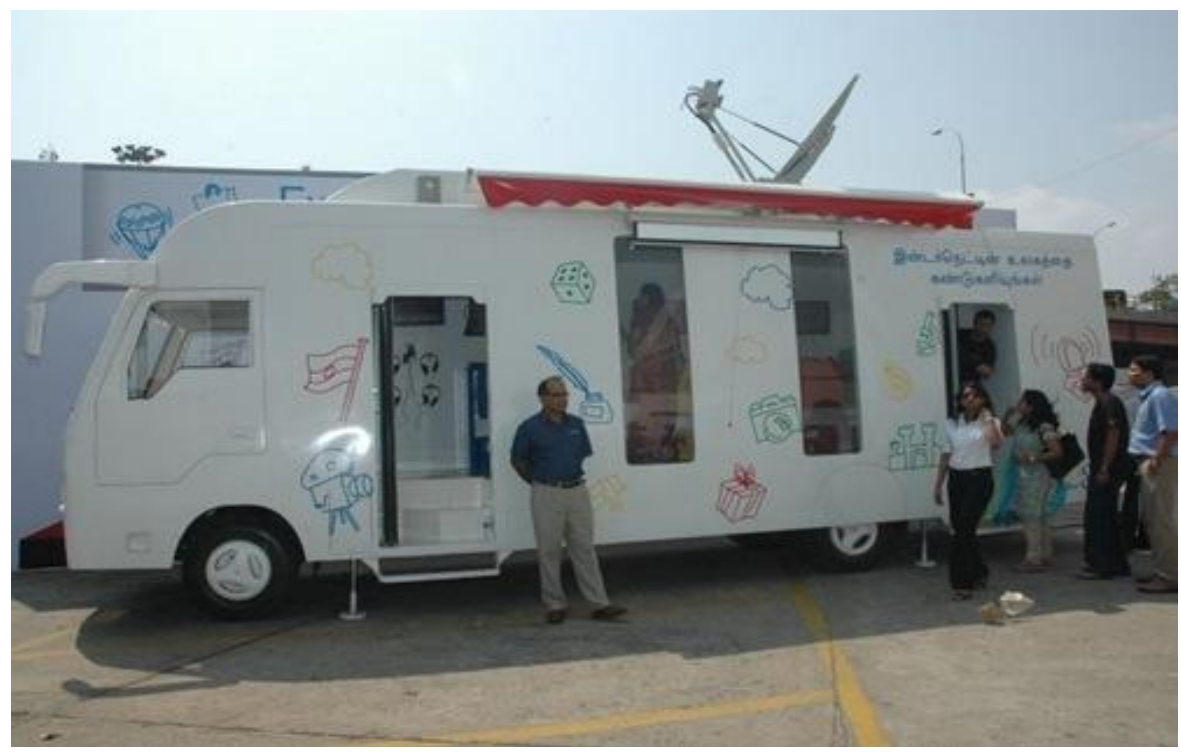

FIGURE XX

GOOGLE BUS INDIA - SIDE VIEW 


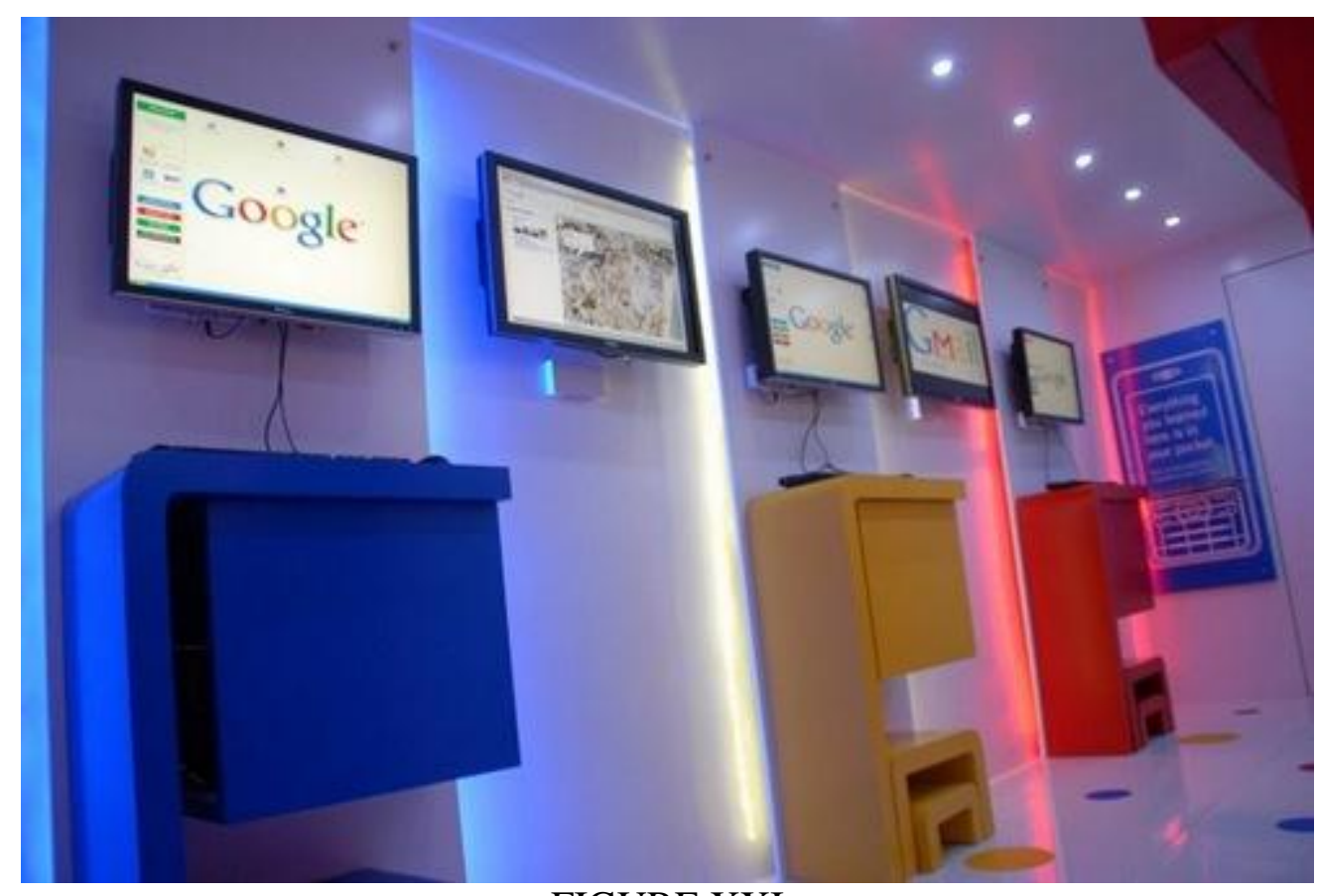

FIGURE XXI

GOOGLE BUS INDIA - INTERIOR

After we completed our discovery and design work, Google attempted a small pilot of a version of our prototype in a smaller country with a smaller, focused population. (However, the pilot was conducted by a marketing group within Google as opposed to an educational group so the goal was increased use or adoption of Google tools rather than educational goals.) Google Bus Bangladesh was launched to train half a million Bangladeshi university and college students in digital literacy at 500 universities and colleges in 35 locations over an entire year ${ }^{48,49}$. A Google Bug Bangladesh Google+ community was created and today has over 50,000 members. The first author helped advise the design of the curriculum. Again, we have no information of the specific goals and targets of the project. We, therefore, do not know if it was considered successful or not.

The current pilot based on our work is the Internet Saathi program which started in 2015 to deliver digital literacy training to 5,000,000 women in 45,000 villages over 18 months in rural India through women cyclists or Saathis ("companions in Hindi"). The Saathis operate like a type of village postwoman to deliver the Internet to particular villages using a bike (Figure XXII $)^{50}$. Each bike contains Internet-enabled devices running the most up-to-date Android operating system and remains in a village 2 days a week for 4 to 6 months ${ }^{50}$. To date, Google claims to have trained or connected over 1.5 million women to the Internet through 9,000 female instructors ${ }^{51,52}$. Additionally, this program is a second iteration on an earlier pilot that used tricycles which were found difficult to steer $^{53}$. 


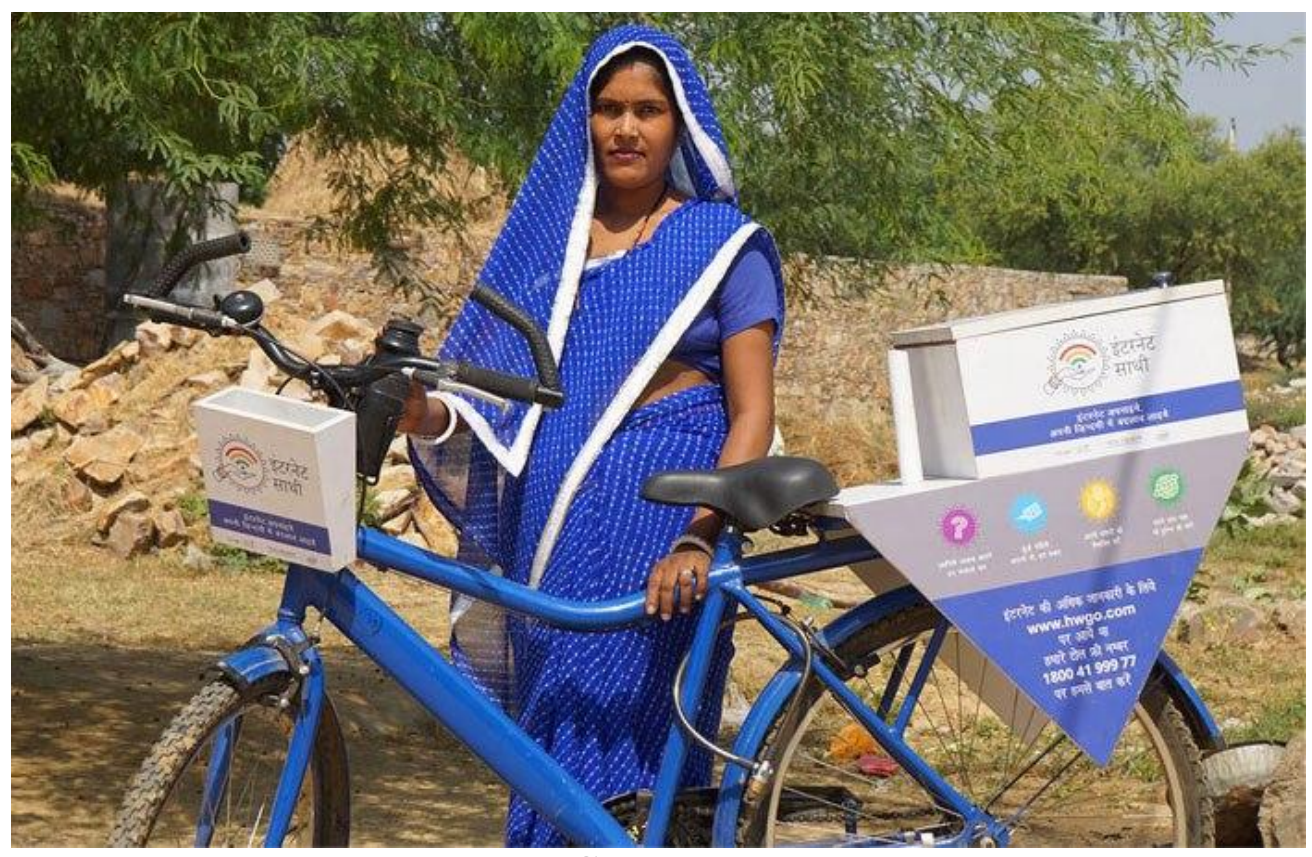

FIGURE XXII

INTERNET SAATHI WITH HER BIKE

\section{CONCLUSION}

In this work, we present the use of a human-centered design methodology to guide the designbased implementation process, creating prototypes digital literacy education for central and Northern India and redesigning our Web Academy digital literacy curriculum. Since instructional design includes not just the design of the content, but also the delivery of the content, our prototypes deal with both the educational content as well as the format and mode of delivery. From the prototyping process it is clear that even if the format of delivery is designed suitably for the community, having the wrong content can make the solution fail to reach its goals. In the same way, the perfect, contextualized, relevant content can fail to reach the community if the delivery and format of the education is poorly designed.

The most important high-level learnings that emerge from our prototyping and piloting work are that given the fact that countries like India and China are majority rural and have more people offline than online, any digital literacy solution must proactively outreach to areas that are not accessing the Internet. We see that in Google's transition from the Helping Women Get Online hotline program to the tricycle program to the Internet Saathi program. Additionally, any digital literacy solution must use local languages as the Internet in local languages continues to grow and members of the target audience do not speak the dominant language.

Second, the content in the training must be highly contextualized and problem-based. Lessons and education that focus on tools or tool functions do not make sense or seem relevant to the vast majority of those who are not yet digitally literate.

Third, our learning theory (from the research phase) that significant numbers of people cannot become digitally literate on their own was reinforced as we only saw one small (Hole-in-theWall) community that had adults who learned without instruction but in a group. 
Fourth, we must incorporate those without reading and writing literacy in order to reach all those with the potential to become digitally literate. Our prototypes primarily focused on those who are already reading and writing literate and addressed others in small ways through auditory options and instructors, for example. The Internet Saathi program addresses through the saathi instructor.

Fifth, all themes that emerged during the research phase still play an active role in the prototyping step. For example, gender-based access is addressed by having all women Internet Saathis.

Sixth, designing a sustainable revenue model is crucial to making sure the pilot succeeds in the delivery stage. The sheer expense of the mobile bus compared to the Internet Saathi program most likely steered Google to pursue the cheaper Internet Saathi option and not continue the Google Bus to other parts of Bangladesh or in India.

Seventh the best prototyping tests are actual design experiments. With our initial prototypes we first received feedback on outlines of curricula and models which is different than testing if people will actually use it or observing how they interact with it. So it was very important to try this out with Google Bus Bangladesh and now Internet Saathis. We will continue to test and iterate and improve those pilots in an effort to spread digital literacy both to men and children and other countries with populations who are not digitally literate.

\section{ACKNOWLEDGEMENTS}

The authors would like to thank Fiona, Natasha, the Web Academy team and 20\% volunteers (Google workers who donate 1 day a week or $20 \%$ of work time to help Web Academy), as well as the Reach program managers, ambassadors, volunteers, and all community groups who participated. 
International Journal for Service Learning in Engineering,

Humanitarian Engineering and Social Entrepreneurship

Vol. 12, No. 1, pp. 13-40, Spring 2017

ISSN 1555-9033

\section{REFERENCES}

1 "Overview: Strengthening the Analog Foundation of the Digital Revolution." World Development Report 2016: Digital Dividends, January 14, 2016, 1-41. Accessed April 12, 2016. doi:10.1596/978-1-4648-0671-1_ov.

2 Pham, Thi Luc Hoa, ICT Development Strategies, (Hamburg: Anchor Academic Publishing, 2014), 81ff .

3 Hunsinger, Jeremy, Lisbeth Klastrup, and Matthew Allen, eds. The International Handbook of Internet Research, (Dordrecht: Springer, 2010), 203.

$4 \quad$ Amiri, Shahram and Brian Reif, "Internet Penetration and its Correlation to Gross Domestic Product: An Analysis of the Nordic Countries," International Journal of Business, Humanities and Technology 3, no. 2 (2013) $50-60$.

${ }_{5} \quad$ Sprague, Kara, James Manyika, Bertil Chappuis, Jacques Bughin, Ferry Grijpink, Lohini Moodley, and Kanaka Pattabiraman. Offline and falling behind: Barriers to Internet adoption, (San Francisco: McKinsey, 2014) $13 \mathrm{ff}$.

6 Katz, Raul. The Impact of Broadband on the Economy: Research to Date and Policy Issues. Geneva: ITU, 2012. Accessed April 8, 2016. https://www.itu.int/ITU-D/treg/broadband/ITU-BB-Reports_Impact-of-Broadband-

$\frac{\text { on-the-Economy.pdf. }}{7 \text { du Rausas, M }}$ Net's sweeping impact on growth, jobs, and prosperity. New York: McKinsey, 2011. Accessed April 8, 2016. http://www.mckinsey.com/industries/high-tech/our-insights/internet-matters.

$8 \quad$ Sprague et al. Offline and falling behind: Barriers to Internet adoption, $30 \mathrm{ff}$.

$9 \quad$ Sprague et al. Offline and falling behind: Barriers to Internet adoption, 8.

$10 \quad$ Cook, James. "This Is The \$33 Smartphone For India That Could Ruin Samsung's Android Business."

Business Insider. 2014. Accessed April 08, 2016. http://www.businessinsider.com/mozilla-33-intex-cloud-fxsmartphone-in-india-2014-8.

$11 \quad$ Brahima Sanou, Foreword to Measuring the Information Society Report 2013 by ITU (Geneva: International Telecommunications Union 2014) iii.

12 Brahima Sanou, Foreword to Measuring the Information Society Report 2014 by ITU (Geneva: International Telecommunications Union 2015) iii-iv.

13 Brahima Sanou, Foreword to Measuring the Information Society Report 2015 by ITU (Geneva: International Telecommunications Union 2016) 2.

14 Brahima Sanou, foreword, iii.

15 Brahima Sanou, foreword, 249.

16 Tinder Foundation. Accessed April 09, 2016. http://www.tinderfoundation.org/

17 McDonald, Catherine. A Leading Digital Nation by 2020: Calculating the cost of delivering online skills for all. London: Tinder Foundation \& Go On UK, 2014. Accessed April 9, 2016.

https://www.tinderfoundation.org/sites/default/files/research-publications/a_leading_digital_nation_by_2020_0.pdf.

${ }_{18} \quad$ Web Academy Online Basics curriculum. Accessed April 09, 2016

https://drive.google.com/drive/u/0/folders/0BxQkc5KBA9IlV1YybG5ja01COWM.

19 Udoewa, Victor, Neil Mathew, Louie Al-Hafidh, Lokesh Bhog, Anuranjan Gupta, Parivartika Patel,

Bhawana Prabhakar, Saummya Kaushik, Lea Bauer, and Valentina Humar. "Helping the Next 4 Billion Go Online Part I: Design Research for Digital Literacy Education." International Journal for Service Learning in Engineering 11, no. 2 (November 2016): 18-37. http://ojs.library.queensu.ca/index.php/ijsle/article/view/6393.

${ }_{20}$ Dabla-Norris, Era, Kalpana Kochhar, Nujin Suphaphiphat, Frantisek Ricka, and Evridiki Tsounta. "Causes and Consequences of Income Inequality: A Global Perspective." IMF Staff Discussion Notes 15, no. 13 (June 2015): 4, 10ff. doi:10.5089/9781513555188.006.

21 Chusseau, Nathalie, and Joël Hellier. "Inequality in Emerging Countries." SSRN Electronic Journal SSRN Journal. doi:10.2139/ssrn.2131360.

$22 \quad$ "Chapter 3. Inequality and Economic Mobility." Economies of Emerging Markets Better Rated During Difficult Times. Pew Research Centers Global Attitudes Project RSS. May 23, 2013. Accessed April 10, 2016. http://www.pewglobal.org/2013/05/23/chapter-3-inequality-and-economic-mobility/.

23 "Special Focus: Inequality in Emerging Economies (EEs)." In Divided We Stand Why Inequality Keeps Rising. Paris: OECD, 2011. Accessed April 10, 2016. https://www.oecd.org/els/soc/49170475.pdf. 
International Journal for Service Learning in Engineering,

Humanitarian Engineering and Social Entrepreneurship

Vol. 12, No. 1, pp. 13-40, Spring 2017

ISSN 1555-9033

Vieira, Sergio. Inequality on the Rise? An Assessment of Current Available Data on Income Inequality, at Global, International and National Levels. Report. December 2012. Accessed April 10, 2016.

http://www.un.org/en/development/desa/policy/wess/wess bg papers/bp_wess2013 svieira1.pdf.

$\frac{25}{25} \quad$ "Implications of Rising Inequality in Emerging Markets." Carnegie Endowment for International Peace. November 17, 2011. Accessed April 10, 2016. http://carnegieendowment.org/2011/11/17/implications-of-risinginequality-in-emerging-markets.

$26 \quad$ "Digital Literacy Definition and Resources." Digital Literacy Definition and Resources. October 15, 2008. Accessed April 11, 2016. http://www.library.illinois.edu/diglit/definition.html.

$27 \quad$ "Enhancing Digital Literacy." What Is Digital Literacy? 2016. Accessed April 11, 2016.

http://schools.nyc.gov/community/innovation/ConnectedFoundations/EDL/default.htm.

$28 \quad$ "ECDL Foundation." ECDL Foundation. 2015. Accessed April 11, 2016.

http://www.ecdl.org/index.jsp?p=826.

$29 \quad$ Jacobson, Robert, ed. "Chapter 4: Human-centered Design." In Information Design, by Mike Cooley, 5981. Cambridge: MIT Press, 2000.

30 IDEO.org. HCD Toolkit. San Francisco: IDEO.org, 2013. 2nd edition.

31 IDEO.org. The Field Guide to Human-centered Design. San Francisco: IDEO.org, 2015. 1st edition.

32 Friedman, Batya, and David Hendry. "The envisioning cards: a toolkit for catalyzing humanistic and

technical imaginations." In Proceedings of the SIGCHI conference on human factors in computing systems, pp. 1145-1148. ACM, 2012.

33 Simonsen, Jesper, and Finn Kensing. "Using ethnography in contextual design." Communications of the ACM 40, no. 7 (1997): 82-88.

$34 \quad$ Millen, David R. "Rapid ethnography: time deepening strategies for HCI field research." In Proceedings of the 3 rd conference on Designing interactive systems: processes, practices, methods, and techniques, pp. 280-286. ACM, 2000.

35 Barab, Sasha A., Michael K. Thomas, Tyler Dodge, Kurt Squire, and Markeda Newell. "Critical design ethnography: Designing for change." Anthropology \& Education Quarterly 35, no. 2 (2004): 254-268.

36 Bang, Megan, Douglas Medin, Karen Washinawatok, and Shannon Chapman. "Innovations in culturally based science education through partnerships and community." In New Science of Learning, pp. 569-592. Springer New York, 2010.

$37 \quad$ Penuel, William R., Samuel Severance, Raymond Johnson, Heather Leary, and Susan Miller. "The Emergence of New Objects in Co-Design: A Cultural-Historical Activity Theoretical Analysis." Proceedings of the 11th International Conference of the Learning Sciences, June 2014. Accessed April 12, 2016.

http://learndbir.org/resources/Negotiating_the_Object_in_CoDesign.pdf.

$38 \quad$ Muller, Michael J., Daniel M. Wildman, and Ellen A. White. "Taxonomy of Participatory Design Practices." Posters and Short Talks of the 1992 SIGCHI Conference on Human Factors in Computing Systems - CHI '92, 1992. Accessed April 12, 2016. doi:10.1145/1125021.1125053.

39 Muller, Grudin, Jonathan, and John Pruitt. "Personas, participatory design and product development: An infrastructure for engagement." In PDC, pp. 144-152. 2002.

$40 \quad$ Anderman, Eric. "Research Methods: An Overview." Research Methods: An Overview. December 23, 2009. Accessed April 11, 2016. http://www.education.com/reference/article/research-methods-an-overview/.

$41 \quad$ Mitra, Sugata. Beyond the Hole in the Wall. TED Books, 2012.

42 Mitra, Sugata, Ritu Dangwal, Shiffon Chatterjee, Swati Jha, Ravinder S. Bisht, and Preeti Kapur.

"Acquisition of computing literacy on shared public computers: Children and the" hole in the wall"." Australasian Journal of Educational Technology 21, no. 3 (2005): 407.

43 Mitra, Sugata, and Ritu Dangwal. "Limits to self- organising systems of learning - the Kalikuppam experiment." British Journal of Educational Technology 41, no. 5 (2010): 672-688.

44 Network for Information and Computer Technology, The Implementation People. 2016. Accessed December 29, 2016. http://www.nict.co.in/.

$45 \quad$ Common Service Centre. 2016. Accessed December 29, 2016. http://www.nictcsc.com/.

46 NICT Computer Education. 2016. Accessed December 29, 2016. http://www.nicteducation.com/nictcenters.html.

$47 \quad$ "India Internet Bus Project rolls in." Official Google Blog. 2009. Accessed December 30, 2016.

https://googleblog.blogspot.com/2009/02/india-internet-bus-project-rolls-in.html. 
International Journal for Service Learning in Engineering, Humanitarian Engineering and Social Entrepreneurship Vol. 12, No. 1, pp. 13-40, Spring 2017

ISSN 1555-9033

48

"Google Bus takes the Internet for a ride across Bangladesh." Google for Education. 2015. Accessed December 30, 2016. http://googleforeducation.blogspot.com/2015/02/Google-Bus-takes-the-Internet-for-a-rideacross-Bangladesh.html.

$49 \quad$ Http://www.youtube.com/channel/UCobYn1_gUKvlTOp7ORW0XuA. YouTube. 2014. Accessed

December 30, 2016. https://www.youtube.com/watch?v=Lg2oXlj03eE.

$50 \quad$ "Google New 'Internet Bikes' News: Search Engine Giant Unveils Program to Empower Rural Indian Women [VIDEO]." BREATHEcast. 2015. Accessed December 30, 2016.

http://www.breathecast.com/articles/google-new-internet-bikes-news-search-engine-giant-unveils-program-toempower-rural-indian-women-video-30832/.

$51 \quad$ Http://www.indianweb2.com/author/kirti/. "After A Year of Its Launch, This Is How Google's Internet Bicycle Is Bringing India's Rural Women Online." IndianWeb2.com. 2016. Accessed December 30, 2016.

http://www.indianweb2.com/2016/10/10/year-launch-googles-internet-bicycle-bringing-indias-rural-women-online/. $52 \quad$ Ians. "Internet Saathi: Transforming lives of women through digital education." The Economic Times.

2016. Accessed December 30, 2016. http://economictimes.indiatimes.com/tech/internet/internet-saathitransforming-lives-of-women-through-digital-education/articleshow/52743134.cms.

$53 \quad$ Reporter, BS. "Google, Tata Trusts roll out bicycles to teach internet to rural women." Business Standard News. 2015. Accessed December 30, 2016. http://www.business-standard.com/article/current-affairs/google-tatatrust-roll-out-bicycles-to-teach-internet-to-rural-women-115070300766_1.html. 